\title{
Espaço São José Liberto como "patrimônio difícil": desafio para o ensino de História
}

Espaço São José Liberto as "Difficult Heritage":

a Challenge to Teaching History

Wesley Oliveira Kettle*

\section{RESUMO}

Este trabalho tem como objetivo analisar a relação entre a memória prisional e o ensino de História a partir de experiências educacionais realizadas no Espaço São José Liberto, buscando compreender as formas como diferentes vozes enfrentam esse passado ao ratificar, contornar ou questionar a história ali apresentada. Apresentaremos algumas reflexões sobre essa discussão, pensando na importância de dar voz aos personagens marginalizados e silenciados. O Espaço São José Liberto faz parte do circuito turístico da cidade de Belém e também recebe visitas de estudantes do ensino básico e universitário. Hoje ele é composto por ambientes que buscam apresentar o potencial mineralógico da Amazônia. No passado, desempenhou entre outras funções a de convento e presídio, guardando uma memória de difícil abordagem.

Palavras-chave: Espaço São José Liberto; memória prisional; ensino de História.

\section{ABSTRACT}

This paper aims to analyze the relation of prison memory and History teaching from educational experiences performed at "Espaço São José Liberto", trying to understand how different voices confront this past when ratifying, deviating and questioning the history there presented. This work will demonstrate some reflections about that discussion, concerning the importance of giving voice to marginalized and silenced characters. The "Espaço São José Liberto" is included in the touristic circuit of the city of Belém, and also receives visits from students of both elementary and university cycles. Nowadays, that space is composed of settings that present the mineralogical potential of Amazon. In the past, it was a monastery and, after, a prison, among other functions, retaining a memory of difficult approach.

Keywords: Espaço São José Liberto; prison memory; History teaching.

\footnotetext{
* Universidade Federal do Pará (UFPA), Belém, PA, Brasil. wesleykettle@ufpa.br
} 
No centro da histórica cidade de Belém do Pará, os turistas e moradores podem encontrar um conjunto arquitetônico bastante importante para a história colonial brasileira. É verdade que muitos desses edifícios erguidos ao longo dos séculos XVII e XVIII foram derrubados pela ação do tempo, outros estão em processo avançado de degradação e um número reduzido foi restaurado pelo poder público com o objetivo principal de torná-los atração turística. Esses espaços agora abrigam restaurantes, salões de arte, auditórios e museus que também passaram a atrair muitas excursões de estudantes de escolas públicas e privadas do ensino básico e do ensino superior.

Um dos importantes centros de atração turística foi denominado em outubro de 2002 pelo governo do Pará de Espaço São José Liberto, fazendo oposição à antiga denominação de Presídio São José, onde os condenados do sistema judiciário cumpriam suas penas, palco de rebeliões violentas que marcaram a história do sistema prisional paraense. Após profunda restauração, o prédio que também é chamado de Polo Joalheiro passou a abrigar exposições de joias e artesanato regionais com o objetivo de ser uma vitrine para os artistas locais comercializarem seus produtos. O que poucos moradores da cidade sabem é do passado colonial desse patrimônio da cidade.

Ao longo dos anos, os governos estaduais conseguiram promover a manutenção desse complexo oferecendo serviços que atendessem não apenas às expectativas do turismo, mas também de professoras e professores de História do ensino básico e universitário interessados em desenvolver aulas em espaços não formais de ensino sobre os mais diversos temas relacionados ao patrimônio histórico e, de maneira menos frequente, sobre o processo de colonização da Amazônia, com destaque para a riqueza arquitetônica civil, religiosa e militar do edifício. Enquanto isso, os relatos de tortura, punições violentas e condições precárias a que foram submetidos os encarcerados são temas discutidos de maneira secundária ou até mesmo são ausentes.

Consideramos o Espaço São José Liberto, que tenta substituir o Presídio São José, como "patrimônio difícil" na medida em que guarda memórias de práticas que ferem direitos humanos, de sofrimento, de segregação e de assassinatos. Assim, este trabalho tem como objetivo analisar a relação entre a memória prisional e o ensino de História a partir de experiências educacionais realizadas no Espaço São José Liberto, buscando compreender as formas como diferentes vozes enfrentam esse passado ao ratificar, contornar ou questionar 
a história ali apresentada. Apresentaremos algumas reflexões sobre essa discussão pensando na importância de dar voz aos personagens marginalizados e silenciados.

A fim de alcançar o objetivo acima referido, lançamos mão da literatura especializada sobre o tema, analisamos o discurso patrimonial oficial presente no Espaço São José Liberto, além de adotarmos a metodologia da história oral temática em entrevistas realizadas com estudantes e docentes da disciplina História do ensino básico, com o intuito de identificar as diferentes visões sobre o patrimônio prisional e apagamentos propostos pelo governo estadual, responsável pelas transformações do edifício histórico, sem desconsiderar as múltiplas percepções construídas a partir da vida escolar dos envolvidos.

Esta reflexão se deve também em grande parte às experiências vivenciadas no âmbito da regência da disciplina "História e Educação Patrimonial", componente curricular ofertada no primeiro semestre para os licenciandos em História da Universidade Federal do Pará do campus universitário de Ananindeua, que proporcionou a um grupo de sessenta estudantes o debate em sala de aula e principalmente durante as aulas de campo, nas quais muitos dos discentes egressos do ensino público relataram estar visitando espaços patrimoniais pela primeira vez. Junto a isso, a interlocução com docentes do ensino básico que levaram suas turmas em excursões ao Polo é extremamente relevante para pensarmos o desafio de enfrentar a "memória difícil" do sistema prisional que constitui o Espaço São José Liberto.

De maneira sistemática, entrevistamos seis docentes do ensino básico, quatro funcionários do Espaço São José Liberto e quatro visitantes. Soma-se um grupo de oitenta e quatro estudantes do ensino básico e universitário que indiretamente forneceram informações que nos possibilitaram desenvolver e apresentar os dados finais dessa investigação. Dentre as instituições de ensino que contam com personagens envolvidos na pesquisa podemos relacionar a Universidade Federal do Pará, Colégio São José e a Escola Estadual Benício Lopes.

Os elementos que nos serviram de fontes nos permitiram perceber que a história do Espaço São José Liberto, com destaque para seu passado como cadeia pública, são bastante atuais para os estudantes no sentido de se relacionar com temáticas como violência policial, tortura, população negra encarcerada, rebeliões e preservação do patrimônio histórico. Observamos como é difícil para as 
instituições governamentais e educacionais abordarem essa herança, escolhendo muitas vezes silenciar as vozes dos personagens marginalizados.

\section{O PASSADO DO ESPAÇO SÃO JOSÉ LIBERTO}

Nas paredes do Espaço São José Liberto podemos ler informações históricas com o objetivo de situar o visitante sobre os usos do edifício até que fosse transformado em um polo joalheiro que oferece produtos fabricados por artesãos locais e a realização de atividades culturais. Já na recepção (Figura 1, sala indicada com o número 1) se destacam fotografias antigas relembrando o passado do Espaço como presídio. Além dos painéis informativos localizados na entrada que tratam sobre as diferentes funções dadas ao prédio, também há outra com o título "O Eldorado na Amazônia: entre o mito e a realidade", anunciando a importância da mineração para a região.

Figura 1 - Arte sobre imagem da Planta baixa do pavilhão inferior do Espaço São José Liberto

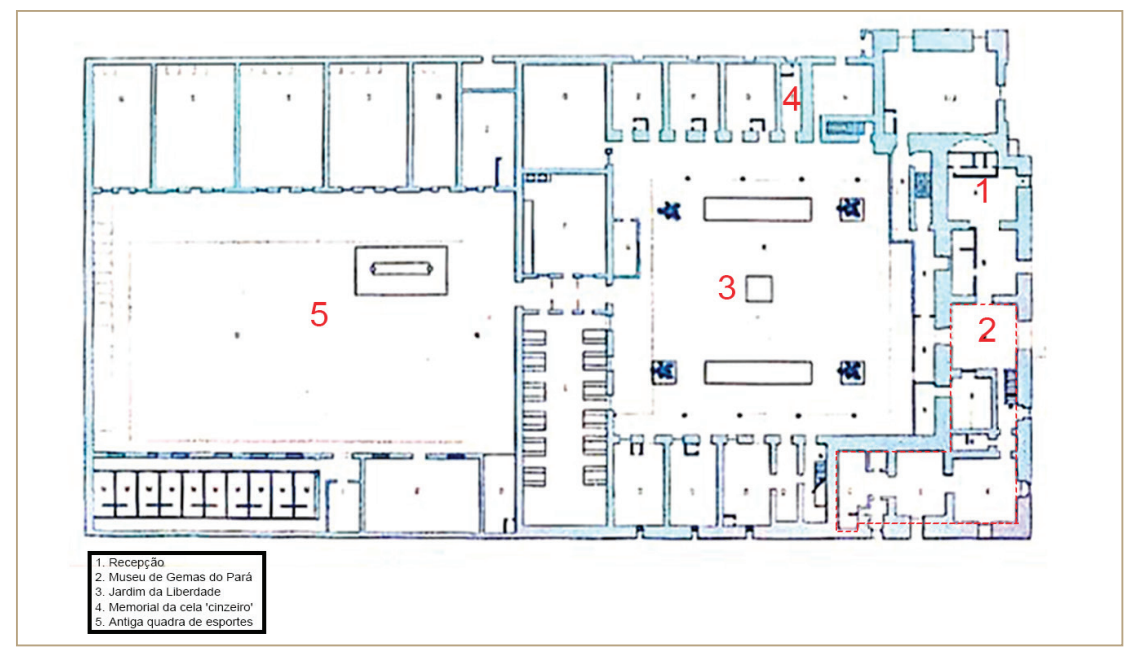

Fonte: Acervo pessoal.

Os relatos dos profissionais que trabalham com a mediação educativa do espaço deixam claro que os professores destacam na recepção a perspectiva his- 
tórica presente nos painéis que fazem parte da recepção. Ao partir do mito do Eldorado, os estudantes são levados a pensar sobre o século XV e as memórias do navegador espanhol Sebastián de Benalcázar, que teria sido um dos principais responsáveis por difundir e registrar a notícia de uma terra com muito ouro e pedras preciosas de posse dos povos indígenas na América espanhola (LANGER, 1997). Com o passar do tempo esse imaginário também influenciou as visões sobre a Amazônia invadida pelos portugueses (GÓMEZ, 1988).

O painel reforça a narrativa dos invasores europeus ao registrar o nome dos militares que capitaneavam as comitivas de exploração que circulavam pelos rios amazônicos. Diego de Lepe, Francisco de Orellana, Gonzalo Pizarro, Pedro de Ursúa e Lope de Aguirre são apresentados como desbravadores que navegaram por uma "trilha fantástica" e tiveram seus planos frustrados por terem sido acometidos por "doenças, mortes e ataques de tribos indígenas". Dessa maneira, os estudantes em visita ao Espaço são levados a reforçar o pensamento eurocêntrico que coloca os povos nativos como barreiras a serem transpostas por aqueles que supostamente traziam a civilização. Essa narrativa parece preparar o olhar do visitante em relação à Amazônia como uma região ainda a ser explorada, inclusive no potencial mineralógico.

O principal texto informativo encontrado na recepção ocupa o centro da sala e trata dos usos da edificação sob o título "Do claustro à liberdade". Os missionários franciscanos são identificados como os primeiros responsáveis pela construção do convento em 1749. O texto destaca a invocação do sítio a São José como forma de possibilitar ao visitante relacionar com a denominação atual do Espaço e identificar a permanência da veneração ao santo. Em seguida, reconhece a doação do terreno aos religiosos por parte de Hilário de Sousa Azevedo, então $13^{\circ}$ capitão-mor do Pará.

Desde a recepção, os textos informativos possibilitam o trabalho com a história da Amazônia no período colonial, ao colocar os estudantes visitantes em contato com uma edificação erigida ainda no século XVIII. Também podem refletir sobre as relações de poder entre militares e as ordens religiosas envolvidas no processo de colonização. Além disso, a apresentação permite discutir os equipamentos arquitetônicos necessários para realizar o projeto de evangelização dos povos indígenas e seus impactos não apenas na paisagem da Amazônia colonial, como nas sociedades indígenas.

Alan Coelho (2002), em obra publicada no âmbito da restauração do pré- 
dio e vinculada à Secretaria de Cultura do Estado do Pará, também inicia a trajetória sobre as diversas funções da edificação pelo convento. Após ampla apresentação sobre a história da atuação dos Franciscanos como ordem religiosa desde Portugal, passando pelo Brasil e sua chegada no Estado do Grão-Pará, o autor reúne valiosas informações sobre o passado do Espaço São José Liberto. Tendo como base uma Carta Régia que trata do falecimento do capitão-mor Hilário de Sousa Azevedo, o documento identifica o terreno doado como nos arredores de Belém, onde já havia uma pequena capela católica.

O documento informa que Hilário de Sousa Azevedo faleceu em expedição ao rio Parú, provavelmente situado na fronteira com o atual Suriname, e seu desejo seria a construção de uma enfermaria que recebesse aqueles que retornassem dos sertões da Amazônia acometidos de doença. De posse dessas informações, os estudantes podem ser encaminhados a pensar sobre as viagens de explorações pelos rios da região e, principalmente, como as enfermidades levaram muitos colonizadores à morte. Nesse momento, o docente já pode observar o potencial do Espaço como patrimônio revelador de uma história que amplia nossa compreensão sobre a Amazônia, mesmo que os fatos apresentados sejam difíceis de serem enfrentados no debate escolar que ainda tende a privilegiar a narrativa vitoriosa dos europeus nessa região.

Em meados do século XVIII, a antiga capela foi demolida para a construção do convento que abrigaria as atividades desenvolvidas pelos frades da Piedade. Alan Coelho (2002, p. 7), utilizando os estudos de Theodoro Braga, informa que, diferente dos demais mosteiros erguidos em Belém, esse convento estava localizado distante das margens da Baía que circundava a cidade. Próximo dali se encontrava o convento de São Boaventura e o igarapé da Comédia dos Peixes-boi (Figura 2, destaque nosso em vermelho indicando a localização do convento), que passou a ser chamado de igarapé São José por causa da construção do convento (BRAGA, 1972, p. 58). Essas notícias permitem a reflexão de como esse patrimônio revela as transformações da paisagem a partir do projeto de colonização que ao longo do tempo não apenas alterou a nomeação de rios e igarapés, mas também trouxe prejuízos para a flora e fauna da região. A mudança do nome de igarapé da Comédia dos Peixes-boi para igarapé São José também marca a diminuição de espécies aquáticas com os aterramentos desses caminhos fluviais, alterando costumes milenares de caça, pesca e alimentação dos povos nativos. 
Figura 2 - Planta geométrica da cidade de Belém do Gram Pará, 1753

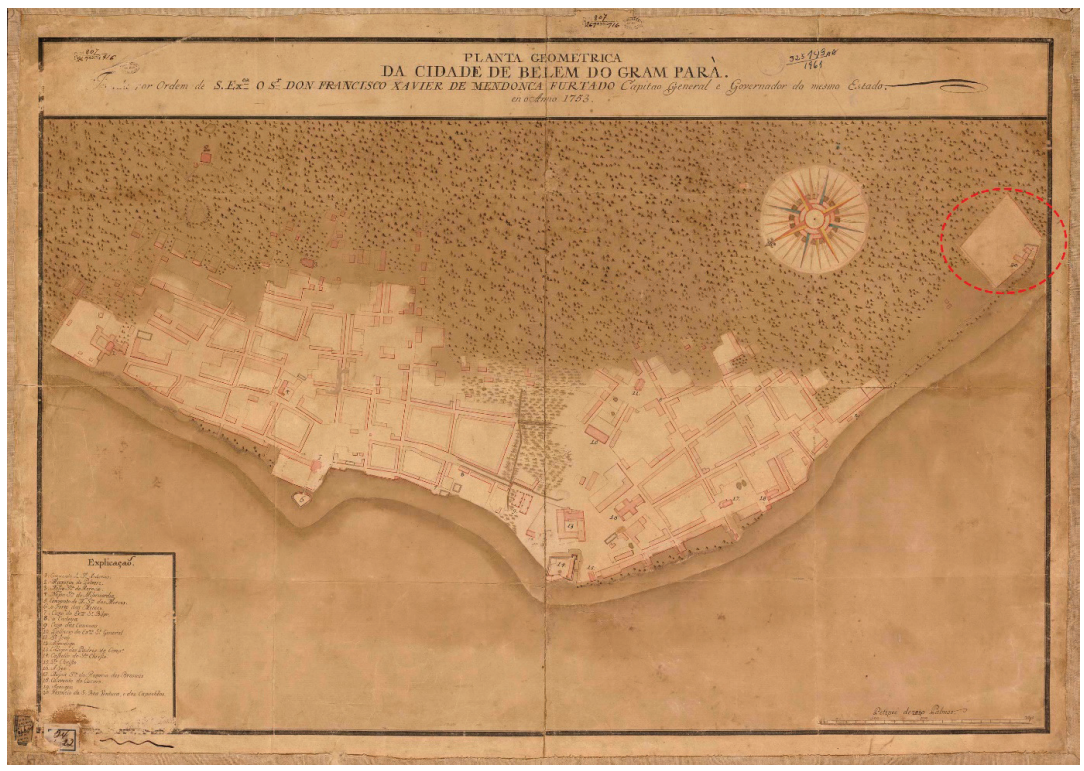

Fonte: http://objdigital.bn.br/acervo_digital/div_cartografia/cart325149/cart325149.jpg

Após dez anos de atividades, os frades da Piedade foram forçados a se retirar do convento e retornar ao Reino por ordem do Governador Francisco Xavier de Mendonça Furtado que expulsou todos os religiosos dessa ordem e também os capuchos da província da Conceição da Beira e do Minho (COELHO, 2000). Diante desse acontecimento, o edifício ficou vago e logo foi procurado pelo governador para servir como depósito de pólvora, elemento explosivo que seria mais bem estocado em áreas distantes das residências e muito importante para as ações militares que baseavam o processo de ocupação portuguesa na América (PIVA e FILGUEIRAS, 2008). A partir dessa segunda função do Espaço, os estudantes podem conhecer o projeto bélico da colonização, pois a pólvora abastecia as arcabuzes das tropas portuguesas que adentravam os sertões amazônicos a fim de escravizar as populações indígenas que se recusavam a deixar suas moradas para servir como mão de obra compulsória.

De forma muito resumida, o painel informativo localizado na recepção do Espaço São José Liberto cita a função de depósito de pólvora e também quartel. É possível pensarmos, portanto, em um passado bastante bélico reve- 
lado nesse patrimônio, na medida em que as forças militares coloniais ocuparam o prédio nos anos da passagem do século XVIII para o século XIX. Segundo Arthur Vianna (1992), o prédio serviu de base para um batalhão de pedestres, uma milícia formada em sua maioria por descendentes de colonizadores que reconheciam os indígenas como inimigos e obstáculos ao controle territorial por parte dos portugueses (OLIVEIRA, 2013). O Espaço também abrigou um esquadrão de cavalaria, regimento militar que seguia orientações do governo local nas ações de combate, choque ou até mesmo reconhecimento (SILVA e RAMOS, 2018), atividades fundamentais para o projeto colonizador que também trouxe muitos prejuízos para as populações nativas.

Seguindo o sentido das funções bélicas, já nos primeiros anos do século XIX, o Espaço serviu de base para o corpo de artilharia, sob o governo de D. Marcos de Noronha (VIANNA, 1992). Essas informações sobre as funções do prédio permitem aos estudantes refletirem sobre o passado violento da Amazônia colonial, onde as armas de fogo e as estratégias de guerra garantiram o avanço dos portugueses sobre as sociedades indígenas. Além disso, revela-se como a narrativa tradicional, que trata da ocupação dessa região por parte dos europeus, pouco ou quase nada apresenta os danos causados aos povos nativos. Os patrimônios históricos que guardam a memória dessa época ainda apresentam dificuldade marcante em discutir a herança desse período que, em grande medida, explica o motivo da população carcerária ter como ancestrais os indivíduos expropriados de suas terras por essas forças militares que em algum momento ocuparam o Espaço São José Liberto.

O painel de entrada também cita o funcionamento do Espaço como olaria. Alan Coelho (2002), a partir dos estudos de Ernesto Cruz (1952), aponta para o reconhecimento da elite local em relação à boa qualidade dos produtos ali fabricados, conquistando fama e destaque dentre outras oficinas ceramistas que comerciavam suas peças e garantiam o trabalho dos construtores da crescente província do Grão-Pará ao longo do século XIX. Ernesto Cruz destaca que os oleiros de São José foram fornecedores de tijolos, mosaicos, telhas, louças, ladrilhos e outros materiais para as famílias mais abastadas com influência política da cidade, que transformavam a paisagem erguendo solares que marcavam a desigualdade social já latente naquela sociedade.

Francivaldo Nunes (2018) demonstra que os arredores da Belém oitocentista foram marcados por olarias quase sempre em conexão com fazendas e engenhos. Os trabalhadores dessas oficinas cerâmicas, em grande parte, des- 
cendiam dos habitantes indígenas da região, expropriados de suas terras pela invasão portuguesa no período colonial, negros escravizados e crianças (CIVILETTI, 2013) que passaram a viver em moradias precárias localizadas ao redor de igarapés e das propriedades concentradas nas mãos dos fazendeiros e senhores de engenho. Dessa mesma forma, os oleiros de São José eram personagens que padeciam com o regime escravocrata e pouco tinham a comemorar da boa fama que as peças ali produzidas gozavam.

De maneira geral, o Espaço São José Liberto pouco faz referência à função de olaria. Não há um painel específico que exalte o reconhecido trabalho desses oleiros como patrimônio histórico na medida em que as peças das mais importantes construções da cidade foram ali fabricadas. Isso pode permitir aos alunos discutir a dificuldade do discurso patrimonial abordar o passado escravocrata na Amazônia e a invisibilidade de trabalhadores da área da construção que, como esses oleiros, foram e continuam sendo desvalorizados apesar de serem fundamentais para a cidade. Atualmente, o Espaço se apresenta como "território criativo" e busca fomentar o comércio desenvolvido por artesãos regionais, iniciativa que de alguma maneira seria ainda mais valorizada caso destacasse a memória do trabalho manual e os oleiros de São José.

A função de hospital também é citada no painel de entrada do Espaço. No ano de 1835, o prédio recebeu feridos das batalhas resultantes da Cabanagem (MAROJA, 2002) e também enfermos no contexto das epidemias de varíola que afligiam Belém (COELHO, 2002). Desde o final do século XVIII e por todo o século XIX, a doença, relacionada com chegada de negros escravizados que desembarcavam nos portos paraenses, fez um número significativo de vítimas, preocupando muito as autoridades pelos grandes prejuízos à economia local (SÁ, 2008). Nesse contexto, o prédio assumia destacada relevância por contribuir com a saúde dos combatentes e demais moradores ali atendidos. O Espaço São José, como patrimônio histórico, guarda memórias de um período difícil pelas precárias condições médicas diante da violência dos combates cabanos e da própria epidemia.

O PASSADO COMO CADEIA E AS

DIFICULDADES DA MEMÓRIA PRISIONAL

Na década de 1840, a cadeia da cidade de Belém apresentava problemas estruturais significativos a ponto de Manoel Paranhos da Silva Veloso, então 
presidente da província, ordenar a transferência dos detentos para o prédio do antigo convento de São José. Após as reformas e adaptações estruturais do edifício, o Espaço foi transformado em Cadeia Pública (COELHO, 2002). Essas notícias são as mais destacadas no painel que informa sobre o patrimônio e também na fala dos mediadores com as quais os estudantes entram em contato durante o percurso da visitação do Espaço São José Liberto. O texto informativo ainda registra a existência da capela, enfermaria, oratório (de função fúnebre), escola para instrução dos presos e um terreno localizado aos fundos do edifício.

Os estudantes se deparam com a informação de que a cadeia passou a receber não apenas homens, mas também mulheres no mesmo espaço prisional e o relato de que negros escravizados eram enviados pelos seus senhores para serem torturados como castigo por alguma ação julgada como indisciplina. Aqui encontramos elementos para considerarmos o Espaço São José Liberto como um "patrimônio difícil", termo definido por Sharon Macdonald (2010) como lugar onde o passado é reconhecido como significativo por parte importante de dada sociedade, mas que revela fatos que incomodam e dificultam a construção de uma narrativa positiva e completamente virtuosa. Esse patrimônio, segundo o autor, faz surgir questões sombrias e polêmicas que reforçam as divisões sociais frente a diferentes interpretações do passado, ameaçando a constituição de uma história uníssona.

Apesar dessa herança difícil, o Espaço São José Liberto não se furtou em apresentar esse passado de tortura e outras questões relacionados ao sistema escravocrata. Durante a visita dos estudantes, a fala dos mediadores também faz referência aos castigos aplicados aos encarcerados na cadeia. Isso proporciona uma reflexão sobre a violência daquele espaço e o projeto de disciplinar os corpos intensificado ao longo de todo o século XIX no Brasil. Os professores de História entrevistados relatam uma importante divisão da turma sobre o castigo aos corpos aprisionados e suscita perguntas como: "naquele tempo não havia como esses presos reclamarem dos maus tratos?" ou "Por que ter pena de bandidos?". Além de comentários como: "bandido bom é bandido morto", "eles só estavam pagando por aquilo que fizeram", "se estivessem trabalhando não estariam ali”, "ninguém merece ser torturado" e "os policiais tinham que ser presos também por fazerem isso".

O Espaço São José Liberto, como patrimônio prisional, possibilita aos 
docentes apresentar discussões sobre as diferentes interpretações do passado, o posicionamento político diante dos fatos históricos e o debate sobre as injustiças sociais que constituem a história. Viviane Borges (2016) afirma que esse conceito de "patrimônio carcerário" é relativamente novo e possível a partir da flexibilização da noção de patrimônio cultural próprio dos anos 1990 e do envolvimento de pesquisadores e historiadores da temática patrimonial. Nossa experiência e os relatos dos professores entrevistados evidenciam que o ensino de História só tende a ganhar com esse tipo de reflexão.

Os registros mostram que os primeiros encarcerados na Cadeia Pública de São José foram negros que padeciam sob o regime da escravidão. O primeiro deles que se tem notícia tinha por nome Inácio e foi aprisionado em 1858, mesmo ano em que Josefa, também negra escravizada, deu entrada na casa penal. Alan Coelho (2002), a partir dos estudos de Alexandre Lima (1999), aponta para o fato de que outras mulheres presas, possivelmente não-escravizadas, são registradas com os nomes de Carolina, Inêz e Teodora, sendo libertadas, mas retornando para cumprimento de pena. Esses dados não estão presentes nos painéis informativos do Espaço, mas são importantes para o ensino de História na medida em que revelam aos visitantes um determinado perfil de condenados: negros, pobres e escravizados.

Os professores que realizaram excursões com turmas do ensino básico ao local relatam que diante desses dados os estudantes não demoram a perceber semelhanças com o perfil da população carcerária que superlota os presídios brasileiros na atualidade e continua em sua maioria negra e de baixa renda (SINHORETTO, 2015). Dessa maneira, a aula de campo propõe o aprendizado a partir de conexões passado-presente e a identificação de permanências na história, especialmente no que se refere às injustiças que marcam a sociedade na América Latina.

Esse tipo de atividade contribui efetivamente para capacitar os alunos a pensar historicamente, que, para Lana Siman e Araci Coelho, é perceber e explicar continuidades na relação presente/passado e futuro. Também permite estabelecer relação entre os acontecimentos e "seus estruturantes de longa e média duração em seus ritmos diferenciados de mudança” (2005, p. 119) e identificar acontecimentos ocorridos no tempo passado que permanecem quase inalterados apesar das muitas transformações sociais, políticas e ambientais no mundo. O Espaço São José e sua memória prisional se apresentam como 
desafios para o ensino de História na medida em que, ao propor aos alunos esse exercício presente/passado, faz emergir patrimônios marginais, de dor, sofrimento, tortura, mutilação, injustiças e outras heranças que suscitam debates nem sempre bem recebidos pelas famílias dos discentes e por parte da coordenação da escola.

Ao analisar os ofícios do administrador da Cadeia Pública, João Gomes da Rocha, pelas décadas de 1870 e 1880, Alan Coelho (2002) identifica a capacidade da Cadeia em aprisionar 150 detentos, mas que apresentava a ocupação média de 80 presos distribuídos em 15 celas, sendo duas delas na função de solitárias. Os dados apontam para um crescimento no número de encarcerados ao longo do tempo e a manutenção do perfil negro e pobre dos punidos. Os professores entrevistados relatam que, em sala de aula, a discussão sobre o aumento da população carcerária instigou de maneira surpreendente as turmas envolvendo inclusive os alunos que não puderam participar da visitação ao Espaço. Também relatam que esse debate dividiu a turma entre aqueles que justificavam a necessidade de "prender mais pessoas" e outros que lamentavam o fato de mais negros e pobres estarem sendo punidos. Aqui, portanto, percebemos um excelente ponto de reflexão sobre as conexões entre o aumento da desigualdade e o encarceramento na história.

Durante o percurso dos estudantes no Espaço São José o conteúdo sobre a história do Brasil Imperial pode ser discutido, com grande destaque para o sistema escravocrata e suas consequências para a formação do nosso país como nação cujos líderes conservaram estruturas desiguais que moldaram a sociedade. O desafio diante da memória prisional ali encontrada é apresentar como o discurso técnico, profissional e oficial musealizado muitas vezes maquia ou silencia patrimônios indesejáveis frutos da experiência escravista. Jacques Le Goff (2003) analisa as disputas em torno da construção da memória coletiva que busca unificar grupos sociais profundamente distintos, valorizando pouco as tradições orais. Nesse sentido, nossas experiências de campo têm sido exitosas quando damos voz aos alunos para que relatem seus conhecimentos sobre o Espaço São José, mesmo que sejam informações dissonantes em relação ao discurso oficial.

Segundo as docentes entrevistadas, outro tema difícil e sensível que marca a visitação ao Espaço São José Liberto é a pena de morte. Samantha Quadrat (2008) identifica a "história sensível" vinculada a questões de trauma e catás- 
trofes no passado. Esses elementos estão presentes em toda experiência de visitação ao Espaço com os estudantes na medida em que para a maioria a descrição das execuções que ocorriam no largo de São José, em frente à Cadeia, causa desconforto, revolta e vergonha pelo passado. A fisionomia da maioria dos alunos é de descontentamento ao saberem que o solo onde pisam foi banhado em sangue de negros e indígenas em sua maioria. Arthur Vianna (1992) descreve com detalhes que os condenados dormiam sua última noite naquela cadeia e, antes de serem enforcados, serviam de principal atração do espetáculo que contava com grande número de espectadores ansiosos por assistir a mais uma execução.

Ao perguntarmos para os alunos qual o motivo das fisionomias com expressões de náusea e repulsa diante desses episódios, muitos responderam que não esperavam que "um lugar tão bonito como aquele" guardasse histórias tão macabras e que a praça em frente, com paisagismo bem conservado e "tão bonito", tivesse um dia sido palco de execuções de pena de morte, enforcamentos bárbaros, violentos e tudo isso em forma de diversão apoiada e assistida pela população. Outros estudantes relacionam as torturas e execuções a relatos sobre fantasmas, almas penadas e assombrações que habitam o Espaço e atormentam os funcionários e visitantes. Tudo isso parece destoar da ideia de Belle Époque, uma cidade supostamente civilizada impulsionada pela economia da borracha. O debate acaba por revelar uma sociedade extremante desigual, violenta e um patrimônio de dor, sofrimento, morte. Um desafio para o ensino de História.

\section{O MEMORIAL DA CELA “CINZEIRO”}

Os professores e mediadores entrevistados relatam que o percurso da visita se inicia pela capela, onde há bancos confortáveis, ar condicionado e todas as condições para apresentar o discurso oficial do Espaço São José que busca destacar o valor patrimonial da edificação. As informações do passado sombrio não são escondidas, pelo contrário, o mediador relata detalhes sinistros que aguçam a curiosidade de grande parte das crianças e adolescentes. Surgem muitas perguntas sobre o funcionamento da cadeia, os procedimentos de tortura, as rebeliões e as histórias de prisioneiros que alcançaram alguma notoriedade. Em seguida, as turmas são levadas para conhecer o Museu de Gemas do Pará, 
recinto interno que compõe o Espaço São José e apresenta a história das pedras preciosas a partir de um acervo com 4 mil peças que buscam marcar o potencial mineralógico do Estado (Figura 1, sala indicada com o número 2).

A primeira informação que chama atenção dos estudantes é a de que as salas do Museu de Gemas também foram nos séculos passados celas para os prisioneiros. O mediador aponta para a espessura das paredes, explica que se mantiveram as grades e ferrolhos que outrora guardavam homens e mulheres considerados ameaças à ordem da cidade pelo Estado e explica que o ambiente acabou por adquirir uma forte energia negativa dado essa utilização. Em meio à penumbra, os estudantes participam de um clima de mistério que colabora para justificar as pedras de quartzo posicionadas com o propósito de reequilibrar a energia positiva do lugar.

Aqui é possível identificar o discurso considerado científico, dados históricos e geológicos sobre os minerais, dividindo o mesmo espaço que o conhecimento sobre poderes dos cristais e pedras preciosas pouco reconhecido pela academia. Os terapeutas holísticos utilizam esses materiais em sessões de cromoterapia e cristaloterapia, revertendo energias negativas dos ambientes. Nesse contexto, o professor de História tem a possiblidade de discutir não apenas os motivos que levaram aquelas salas a serem percebidas como mal-assombradas e de energia negativa, mas também discutir as interações entre o conhecimento científico e os saberes populares.

O Museu de Gemas distribui seu acervo ao longo de cinco salas à meia-luz. O ar de mistério envolve as turmas que ali visitam e encontram um conjunto de peças cerâmicas de origem marajoara e tapajônica. A perspectiva arqueológica é evocada para reforçar a narrativa sobre os exploradores e as riquezas encontradas sob o solo da região. Os professores entrevistados relatam que os estudantes "ficam maravilhados com tanta beleza e riqueza apresentadas no Museu". No entanto, os docentes reconhecem que o debate sobre a concentração de capital a partir da exploração mineralógica nas mãos das elites e a segregação dos povos originários, dos negros e de seus descendentes pouco é desenvolvida para que possa impactar e fazer a turma refletir sobre as consequências para a sociedade amazônica atual.

Após conhecer o Museu de Gemas, as turmas são levadas ao pátio onde os presos tomavam sol. Ali se encontram cristais de quartzos e ametistas organizados em formato de mandala rodeados por um belo conjunto de plantas orna- 
mentais que são apresentados como Jardim da Liberdade e museu de cristais a céu aberto (Figura 1, sala indicada com o número 3), fazendo contraposição ao passado carcerário e de rebeliões. É repetido o discurso da necessidade de harmonização do ambiente por meio dos cristais que dissipam as energias negativas oriundas dos anos em que o Espaço São José Liberto viveu tempos de violência, castigos físicos, assassinatos e todo tipo de problema próprio das casas prisionais. Essa nova função do pátio deixa muito claro o esforço do Estado em substituir a memória da cadeia, ao mesmo tempo em que reclama o título de patrimônio histórico vinculado a esse mesmo passado incômodo.

O Espaço São José Liberto é um patrimônio difícil para o ensino de História pelo fato de apresentar aos alunos essa contradição na construção do discurso que faz a comunidade perceber seu valor histórico para a cidade a partir de seu passado sombrio. Os cristais de quartzo colocados no pátio, se pudessem, harmonizariam não só o ambiente físico, mas também a própria história do edifício. Myriam dos Santos (2005) destaca, em seus estudos, a importância de percebermos esse planejado trabalho de preservação e apagamento de parte da memória de instituições patrimoniais. Isso nos remete às colocações de Pierre Nora quando mostra que a memória não é espontânea ou natural e sim provocada também por meio de lembranças fúnebres (NORA, 1993), como é o caso do Espaço São José. Cabe aos professores de História não naturalizarem os cenários musealizados, mas sim discutirem as intenções políticas que os formaram.

A professora de História Juliene da Silva, uma das docentes entrevistadas no âmbito de nossa pesquisa sobre a educação patrimonial e o ensino de História, relata-nos que, todos os anos, escolhe levar suas turmas que cursam o sexto ano do ensino fundamental por reconhecer no Espaço São José Liberto possibilidades de trabalhar não apenas um conteúdo escolar, mas por encontrar ali pontos para debater sobre a história colonial, imperial, republicana e o tempo presente - inclusive ao perceber o entorno do prédio. Além de concordarmos com essa ideia, consideramo-la nobre e perspicaz na medida em que pode despertar nos alunos a habilidade de reconhecer o que Fernand Braudel identifica como camadas de tempo sobrepostos (1983). Os patrimônios difíceis, por assim dizer, apesar de se apresentarem como desafios para o ensino de História, revelam oportunidades de discutirmos com os alunos a comple- 
xidade da constituição patrimonial e a própria escrita da História diante dos silenciamentos e apagamentos seletivos.

$\mathrm{Na}$ área do Jardim da Liberdade, as turmas se depararam com o Memorial da cela "cinzeiro' (Figura 1, sala indicada com o número 4), "solitária” onde os prisioneiros considerados mais perigosos eram punidos com o isolamento. Os professores apontam como o local que mais chama atenção dos estudantes, principalmente por ser um espaço extremamente reduzido em relação às demais celas, escura, onde o público pode conhecer os objetos de tortura com os quais os encarcerados eram punidos ou castigavam outros presos, revelando uma espécie de poder paralelo e hierarquia dentro da cadeia. Certamente é o ponto mais impactante de toda a visita e expõe o contraste entre o potencial mineralógico apresentado por meio das pedras preciosas que justificam o título de Polo Joalheiro ao Espaço e a memória mais cruel e sombria da cela "cinzeiro".

Não há registros oficiais sobre a origem da denominação de "cinzeiro" para essa "solitária". O mediador Claudyr Diniz, por nós entrevistado, conta-nos que ainda nos tempos de olaria e depósito de pólvora, a cela foi destinada para o descarte de resíduos. A expressão também parece evocar um significado pejorativo, lugar onde se descarta tudo aquilo que perdeu a importância, consumido pelo fogo. O depoimento dos professores entrevistados deixa claro que, apesar desse sentido negativo, é o "cinzeiro" o espaço que ganha mais destaque nos relatórios ${ }^{1}$ entregues pelos alunos como atividade resultante da visita. As informações sobre os castigos e o sofrimento da vida naquela cela ocupam boa parte das redações apresentadas pelas turmas. Os alunos expressam terem sentido uma "energia negativa" e um "clima pesado" que destoa dos demais espaços do Polo Joalheiro.

Em grupos pequenos de até 15 pessoas, os estudantes podem entrar no Memorial da cela "cinzeiro" e conhecer algumas fotografias, painéis informativos e, principalmente, a exposição dos objetos de tortura que contam uma parte da história da "solitária". Os professores relatam que as turmas ficam ansiosas para a entrada na cela e brincam uns com os outros sobre prendê-los ali para sempre. Após conhecerem o recinto, boa parte dos estudantes mudam sua percepção e as brincadeiras diminuem substancialmente, pois alguns são bastante impactados com a experiência. Alguns docentes identificam uma maior sensibilidade por parte das meninas. A maioria dos estudantes do sexo 
masculino reagem sem tanto medo ou espanto. Ao contrário, comentam de forma até efusiva como deveriam acontecer as sessões de castigo.

Marília Pinto de Carvalho (2001) aborda em seus estudos a importância de percebermos como a educação tem tratado de formas diferentes meninos e meninas ao longo do tempo e que isso impacta decisivamente as maneiras de ler o mundo desses dois grupos. A autora também aponta para as diferentes compreensões que os docentes possuem de acordo com o gênero, aprofundando em alguma medida essas diferenciações. À parte toda polêmica que essa constatação dos professores entrevistados possa trazer, cabe destacar que a aula de campo é uma experiência que nos permite observar com mais clareza como os estudantes reagem de maneiras diferentes diante dos monumentos e, nesse contexto, constituem grupos nos quais seus colegas se comportam de modo semelhante.

Diante de patrimônios de difícil abordagem, como o Espaço São José Liberto e em especial o Memorial da cela "cinzeiro", em que meninos e meninas tendem a se comportar de maneira distinta, é importante que os professores estejam atentos para que, durante a apresentação diante da cela e principalmente nos momentos de debate sobre a visita, as diferentes reações possam ser analisadas e toda a turma reflita sobre os motivos que levam cada um de nós a compreenderem o passado de modo distinto. Acreditamos que exageros pontuais na fala de um ou outro estudante devam ser tratados com atenção, não para a uniformização das ideias sobre o patrimônio, mas para corrigir preconceitos e discursos de ódio que possam surgir diante da memória prisional.

Ao entrar no Memorial da cela "cinzeiro", os estudantes encontram à sua esquerda um painel informativo bastante degradado que parece conter uma breve história dos usos da cela, a planta baixa do pavilhão inferior, a planta baixa do pavilhão superior (ambas quando na situação de presídio), ao fundo uma grande fotografia quase em tamanho real da situação supostamente encontrada pelas forças policiais da cela após a última rebelião de presos em março de 1998 e, à direita, vemos a exposição dos objetos de tortura. O mediador Claudyr Diniz relata que os estudantes esperam ansiosos para conhecer o interior do "cinzeiro", mas alguns coordenadores que já conheciam as histórias sobre a "solitária", de maneira discreta, preferem não entrar na cela e aguardar a turma no Jardim da Liberdade.

Diferente do Museu de Gemas do Pará, no Memorial da cela "cinzeiro", as turmas se deparam com um patrimônio sombrio, marginal e de dor. Con- 
sideramos esse ponto como o mais desafiador para o ensino de História, na medida em que apresenta lembranças incômodas para a sociedade dita civilizada, e requer dos professores de História grande habilidade para analisar o discurso sobre o passado da cadeia, a expografia e cenografia museal e, principalmente, os objetos de tortura. É muito importante propor aos alunos que pensem sobre as mudanças que aquele espaço sofreu para dar lugar a todo conjunto de elementos que o transforma em Memorial, desconfigurando a função da cela para isolamento e dos artefatos.

Consideramos elogiável o fato dos administradores públicos, ao conceberam o Espaço São José Liberto, cuidarem em preservar a memória do "cinzeiro" e oferecer ao público escolar a oportunidade de refletir sobre o passado sombrio das Cadeias. No entanto, é perceptível a tentativa de suavizar a apresentação de modo que não agrida os visitantes (dentre eles turistas e estudantes). Isso é observado em uma das legendas que denominam com eufemismo os instrumentos de tortura como "objetos de sevícia", sendo eles uma palmatória com a inscrição à lápis e letras maiúsculas "Sheila/Use e Abuse" e um pênis, ambos de madeira (Figura 3). Os professores relatam que esses artefatos são os que mais impactam os alunos por remeterem a cenas de profunda agressividade.

Figura 3 - Palmatória e pênis de madeira expostos no Memorial da cela "cinzeiro"

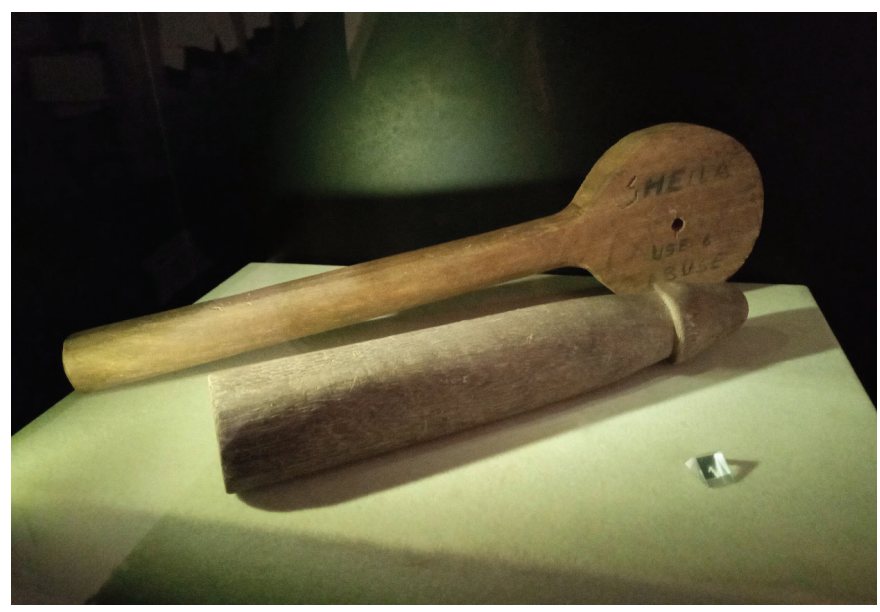

Fonte: Acervo pessoal. 
Além dos instrumentos de tortura, os estudantes também podem observar vergalhões, pregos, colheres e diversos objetos de perfuração, como facas rústicas fabricadas de forma artesanal a partir de pedaços de madeira e ferro encontrados na cadeia (Figura 4). A exposição também conta com uma agulha artesanal para tatuagem que chama muita atenção da maioria dos estudantes pela criatividade da combinação das peças que forma a engenhoca.

Figura 4 - Utensílios de cozinha e perfurantes expostos no Memorial da cela "cinzeiro"

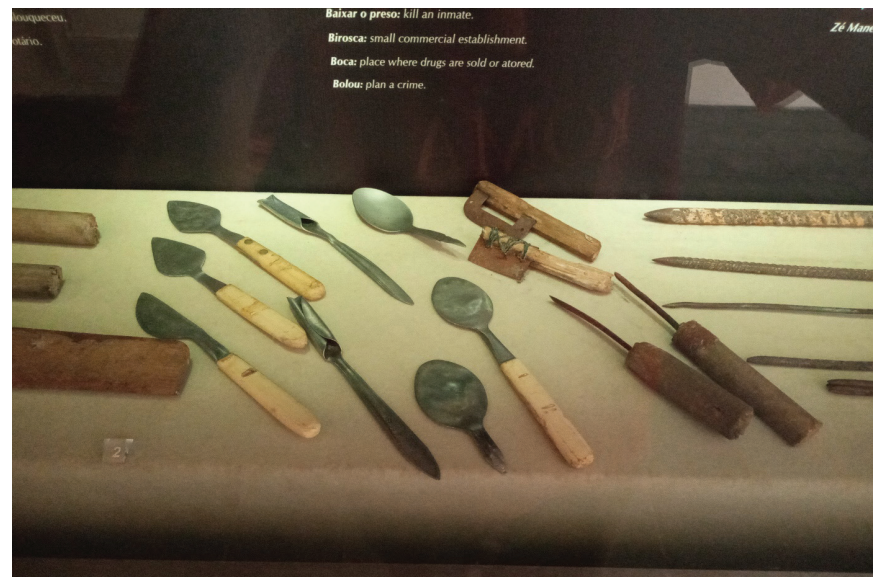

Fonte: Acervo pessoal.

Outra possibilidade para o ensino de História é encaminhar a discussão sobre os objetos expostos como fontes históricas. Circe Bittencourt (2004) adverte para os dados sobre os costumes, técnicas e condições de vida revelados nos objetos musealizados. A partir dessa perspectiva, informações sobre o passado podem ser obtidas a partir da "leitura" dos objetos de tortura, transformando-os em "documentos históricos". A referida autora reconhece que a "potencialidade de um trabalho com objetos transformados em documentos reside na inversão de um 'olhar de curiosidade' a respeito de 'peças de museus' [...] em 'um olhar de indagação' de informação que pode aumentar o conhecimento" sobre o passado (2004, p. 355). Flávia Caimi (2008) considera o trabalho com fontes no ensino/aprendizado de História essencial para "problematizar a realidade, a percebê-la como uma construção histórica, não como 
um dado natural". Tratando-se dos patrimônios sombrios isso se torna ainda mais latente e instigante para alunos e professores.

Assim, a palmatória informa sobre o castigo que marcava as mãos dos prisioneiros, o pênis de madeira denuncia que a violência sexual faz parte dos castigos aplicados, talvez não só pelos funcionários da cadeia, mas também pelos próprios presos que torturavam outros encarcerados estabelecendo um código de conduta e poder paralelos. As correntes, ferrolhos e bolas de chumbo nos remetem às masmorras medievais. Os utensílios de cozinha resgatam a lembrança de que os condenados também mantinham uma rotina de refeições comum. A agulha artesanal revela a importância da prática de tatuagem como recurso e linguagem própria do universo prisional (PAREDES, 2003). Os instrumentos perfurantes contam as histórias de tentativas de assassinatos, mutilações e rebeliões que marcaram a cadeia.

Apesar da cenografia seguir o mesmo padrão do Museu das Gemas, o clima museal pouco ameniza a apresentação de um patrimônio de difícil abordagem na medida em que remete ao passado marginal não apenas daquela cela, mas revela todo um conjunto de práticas que violam o que hoje se reconhece como Direitos Humanos.

Os estudos de Cinthia Araújo apontam para a importância de estabelecer conexões efetivas entre o ensino de História e práticas que conscientizem os alunos do valor dos Direitos Humanos. A autora adverte para a defesa dessas conquistas humanitárias diante dos ataques por parte dos que disputam o poder político, forças autoritárias, os preconceitos arraigados e os agentes que exploram a economia, o que torna o tema indispensável no ambiente escolar. Ela amplia o debate propondo ações educativas e metodologias que insiram o tema também nos espaços não formais de ensino com o objetivo de "criar uma cultura de paz, de reconhecimento e de valorização das diferenças e de engajamento nos processos de redistribuição e minoração das desigualdades, com o intuito de promover a transformação social” (2013, p. 68).

Nesse sentido, a abordagem de patrimônios difíceis com o Memorial da cela "cinzeiro" possibilita ao professor de História refletir sobre a importância dos Direitos Humanos, posicionando-se contra os castigos físicos e o uso da tortura como punição utilizada pelas forças de segurança. É possível identificar falas de alunos que porventura possam apoiar as execuções sumárias e palavras de ordem como "bandido bom é bandido morto". Consideramos que o papel 
do docente é discutir a complexidade da desigualdade social e a segregação que marcam a história do Brasil e que estão diretamente relacionadas à composição da população carcerária. Dessa maneira temos a oportunidade de colaborar com a "cultura de paz" e a transformação social.

\section{CONSIDERAÇÕES FINAIS}

O último ambiente a ser visitado pelas turmas é o segundo pátio (Figura 1, sala indicada com o número 5) que se pode acessar pelo Jardim da Liberdade. O mediador explica que a partir da década de 1940, durante o governo do interventor Magalhães Barata, os presos passaram a utilizar aquele espaço para a prática de esportes e o trabalho nas oficinas que fabricavam vassouras, sapatos, bordados em madeira e outras atividades manuais. Alan Coelho (2002, p. 16) aponta que foi nesse período que a Interventoria do Pará promoveu reformas no edifício para o adequar à função de presídio sob a filosofia de que apenas o trabalho diligente poderia desenvolver a economia do estado.

Os textos contidos nos painéis pouco destacam a relação entre o governo de Magalhães Barata e as mudanças não apenas na estrutura da cadeia, sua transformação em presídio, mas, principalmente, no modo mais firme e duro de tratar os prisioneiros. Talvez por causa disso, o Espaço São José Liberto preferiu não expor esses fatos. No entanto, há uma memória construída a partir dos relatos de moradores mais antigos da cidade, que reconhece Magalhães Barata como o interventor que tornou ainda mais severos os castigos aplicados no Presídio São José. Relatos não oficiais contam sobre execuções clandestinas, tortura e desaparecimento de cadáveres. A fama autoritária foi reforçada por notícias, que ainda hoje circulam, de que presos eram levados para a floresta e, após serem mortos, as marcas no chão eram apagadas pelos policiais utilizando o cacho do açaizeiro sem os frutos e também que condenados eram lançados no meio dos rios próximos da cidade com bolas de aço presas ao tornozelo.

Nesse momento de interação, no qual os estudantes têm a oportunidade de falar sobre essas memórias contadas pelos seus familiares mais antigos, podemos identificar um maior interesse das turmas em relação ao passado do Espaço. Surgem mais uma vez relatos sobre fantasmas e almas penadas que assombram o prédio, especialmente os funcionários que trabalham na segu- 
rança noturna, mas também notícias de aparições inexplicáveis durante o dia, gritos, gemidos, copos de água que secam instantaneamente, barulhos de molho de chaves e metais batendo nas grades. A partir de então, alguns estudantes ficam até apreensivos e receosos de ir ao banheiro (adaptado de uma cela) sozinhos.

Nesse sentido, identificamos a oportunidade de discutir com os estudantes esses relatos não oficiais como elementos que contribuem para a formação do Espaço São José como um Patrimônio Histórico. Apesar de não ter sido explorado pelos responsáveis na revitalização e transformação dos ambientes com objetivo turístico, esses causos que em alguma medida dialogam com o tema do sobrenatural e a morte, dão vida ao lugar. Nossa sugestão é de que os professores valorizem essa dimensão quase mística e analisem como essas histórias parecem estar mais firmes na memória popular do que aquelas registradas nos painéis informativos e livros que tratam do Espaço São José Liberto.

Os estudantes ainda podem observar as referências feitas às rebeliões que ocorreram naquele prédio. Os professores e funcionários entrevistados reconhecem esses episódios como o passado mais difícil a ser abordado com as turmas. A última rebelião, ocorrida em 28 de fevereiro de 1998, foi iniciada a partir da reivindicação dos presos contra a superlotação do presídio que possuía a capacidade de 150 vagas, mas aprisionava 280 condenados. O governo estadual mobilizou 400 policiais para encerrar a revolta que teve fim após a morte de 3 presos, um deles chamado José Augusto Viana, conhecido pela população como o perigoso "Ninja".

Os funcionários e professores entrevistados relatam episódios em que, durante a visita, alguns estudantes não se sentiram bem e se emocionaram diante da experiência de vivenciar o lugar. Essas pessoas parecem ter alguma ligação com familiares que trabalharam ou mesmo foram aprisionados naquelas celas. O choro muitas vezes demonstra uma extrema necessidade com a história do Espaço São José Liberto. É importante considerar que as transformações do Espaço para atender aos interesses turísticos não foram capazes de apagar o passado de tortura e morte para alguns visitantes. Neste ponto temos a certeza de que o Espaço é um patrimônio de difícil abordagem para o ensino de História.

O Espaço São José Liberto nos apresenta uma história ligada ao aprisionamento, desde a sua atividade inicial como claustro religioso até a função 
mais recente de cadeia pública e presídio. Apesar do passado sombrio, consideramos que o desafio de abordar patrimônios difíceis como o Espaço São José Liberto deva ser enfrentado pelos docentes pelo fato de possibilitar discussões sobre o apagamento da história de personagens marginalizados na sociedade brasileira desde o período colonial e o silenciamento das vozes e gemidos de homens e mulheres que tiveram seus corpos torturados nesses espaços. Além disso, temos a oportunidade de questionar visões preconceituosas e discursos de ódio que porventura possam estar orientando, em menor ou maior grau, o pensamento dos estudantes.

Assim, propomos um ensino de História que considera todo o potencial das aulas em espaços não formais e que aceita o desafio de afirmar a importância dos Direitos Humanos em meio aos ataques do mau revisionismo histórico que pretende desvalorizar a luta dos povos marginalizados, especialmente negros e indígenas. Revela-se, portanto, as consequências de uma sociedade que tem como marca as injustiças sociais que devem ser criticadas no espaço escolar com o objetivo da promoção de um espírito cidadão de luta pelas liberdades e igualdades. Nossa análise das experiências relatadas pelos professores e funcionários entrevistados e as sugestões de abordagem buscam fortalecer o vínculo entre a educação e a cultura de não violência, contra a tortura e pela paz.

\section{REFERÊNCIAS}

ARAÚJO, Cinthia Monteiro de. Alianças entre o PNEDH e o ensino de história: concepções docentes sobre as relações entre educação e direitos humanos. Educação, Porto Alegre, v. 36, n. 1, p. 67-73, 2013.

BITTENCOURT, Circe Maria Fernandes. Ensino de História: fundamentos e métodos. São Paulo: Cortez Editora, 2018.

BORGES, Viviane Trindade. Carandiru: os usos da memória de um massacre. Revista Tempo e Argumento, Florianópolis, v. 8, n. 19, p. 04-33, 2016.

BRAGA, Theodoro. Teses para conferências didáticas nas escolas públicas e particulares do Estado do Pará. In: BRAGA, Theodoro. Theodoro Braga no Centenário do seu Nascimento. Belém: Conselho Estadual de Cultura, 1972.

BRAUDEL, Fernand. O Mediterrâneo e o mundo mediterrânico na época de Filipe II. 2 vols. Lisboa: Publicações Dom Quixote, 1983. 
CAIMI, Flávia Eloisa. Fontes históricas na sala de aula: uma possibilidade de produção de conhecimento histórico escolar? Revista Anos 90, Porto Alegre, v. 15, n. 28, p. 129-150, 2008.

CARVALHO, Marília. Mau aluno, boa aluna? Como as professoras avaliam meninos e meninas. Revista Estudos Feministas, Florianópolis, v. 9, n. 2, p. 554-574, 2001.

CIVILETTI, Maria Vittoria Pardal. O cuidado às crianças pequenas no Brasil escravista. Cadernos de Pesquisa, São Paulo, n. 76, p. 31-40, 1991.

COELHO, Alan Watrin. São José Liberto, joias e artesanato do Pará: pesquisa histórica acerca do Presídio São José. Belém: SECULT, 2002.

COELHO, Geraldo Mártires. A pátria do Anticristo: A expulsão dos jesuítas do Maranhão e Grão-Pará e o messianismo milenarista do Padre Vieira. Luso-Brazilian Review, Wisconsin: University of Wisconsin Press, v. 37, n. 1, p. 17-32, 2000.

CRUZ, Ernesto. Procissão dos Séculos. Belém: Imprensa Oficial, 1952.

DA SILVA, Wiliam Vinícius Vargas; RAMOS, Gustavo Linhares. A Cavalaria Brasileira - sua origem, desenvolvimento e evolução. $O$ adjunto: revista pedagógica da escola de aperfeiçoamento de sargentos das armas, Cruz Alta, v. 6, n. 1, p. 57-64, 2018.

GÓMEZ, Oscar Gerardo Ramos. Sebastián de Benalcázar: conquistador de Quito y Popayán. Madrid: Anaya, 1988.

LANGER, Johnni. O mito de Eldorado: origem e significado do imaginário sul-americano (século XVI). Revista de História, São Paulo, n. 136, p. 25-40, 1997.

LE GOFF, Jacques. História e memória. Campinas: Ed. Unicamp, 2003.

LIMA, Alexandre Caleja. Proposta de Restauração e Reciclagem do presídio São José. Trabalho de Conclusão de Curso (Graduação em Arquitetura e Urbanismo). Faculdade de Arquitetura e Urbanismo, Universidade da Amazônia. Belém, 1999.

MACDONALD, Sharon. Difficult heritage: Negotiating the Nazi past in Nuremberg and beyond. New York: Routledge, 2010.

MAROJA, Ana Paula. O Espaço São José (Belém-PA): liberto dos grilhões da lei e preso às imagens do tempo. Trabalho de Conclusão de Curso (Graduação em Educação Artística - Habilitação em Desenho). Curso de Educação Artística: Universidade da Amazônia. Belém, 2002.

NORA, Pierre. Entre memória e história: a problemática dos lugares. Tradução: Yara Aun Khoury. Projeto História (Revista do Programa de Estudos Pós-graduados em História/Departamento de História, PUC-SP), São Paulo, v.10, p.7-28, 1993.

NUNES, Francivaldo Alves. Nas cercanias da Belém oitocentista: entre fazendas, sí- 
tios, olarias e engenhos. Revista do Instituto Histórico e Geográfico do Pará, Belém, v. 5, n. 01, 2018.

OLIVEIRA, Mayra Cardoso Baêta de. As companhias milicianas de pedestres no Maranhão (década de 1820). In: Anais do III Simpósio de História do Maranhão Oitocentista: impressos no Brasil do século XIX. São Luís, 2013. p. 1-7. Disponível em: https://docplayer.com.br/8465698-As-companhias-milicianas-de-pedestres-no-maranhao-decada-de-1820.html. Acesso em: 18 out. 2020.

PAREDES, Cezinando Vieira. A influência e o significado das tatuagens nos presos no interior das penitenciárias. Monografia (Especialização em Tratamento Penal e Gestão Prisional). Universidade Federal do Paraná. Curitiba, 2003. pp. 40. Disponível em: http://www.depen.pr.gov.br/arquivos/File/monografia_cezinando.pdf. Acesso em: 18 out. 2020.

PIVA, Teresa C. C.; FILGUEIRAS, Carlos A. L. O fabrico e uso da pólvora no Brasil colonial: o papel de alpoim na primeira metade do século XVIII. Química Nova, São Paulo, v. 31, n. 4, p. 930-936, 2008.

SÁ, Magali Romero. A "peste branca” nos navios negreiros: epidemias de varíola na Amazônia colonial e os primeiros esforços de imunização. Revista Latinoamericana de Psicopatologia Fundamental, São Paulo, v. 11, n. 4, p. 818-826, 2008.

SANTOS, Myrian Sepúlveda dos. Os conflitos entre natureza e cultura na implementação do Ecomuseu Ilha Grande. História, Ciência, Saúde. Manguinhos, v. 12, p. 381-400, 2005.

SIMAN, Lana Mara de Castro; COELHO, Araci Rodrigues. O papel da mediação na construção de conceitos históricos. Educação e Realidade, Porto Alegre, v. 40, n. 2, p. 591-612, 2015.

SINHORETTO, Jacqueline. Mapa do encarceramento: os jovens do Brasil. Secretaria Nacional da Juventude, 1 ${ }^{\text {a }}$ Edição. Brasília: Presidência da República, 2015.

\section{NOTAS}

${ }^{1}$ Os docentes entrevistados relataram a produção de relatórios da visita por parte dos estudantes. No entanto, a análise dessas atividades não faz parte da reflexão desenvolvida neste artigo, apesar de reconhecer sua importância e seu potencial para a investigação do tema.

Artigo submetido em 27 de outubro de 2020. Aprovado em 28 de janeiro de 2021. 